\title{
Cooperação Brasil-Timor-Leste sob o paradigma do dom e da hospitalidade
}

\author{
Brazil-East Timor cooperation under the gift \\ and hospitality paradigm
}

DOI: $10.21530 /$ ci.v14n2.2019.881

\author{
Silvia Garcia Nogueira ${ }^{1}$ \\ Wemblley Lucena De Araújo ${ }^{2}$
}

\section{Resumo}

O presente artigo discute, a partir de uma pesrpectiva crítica, o processo de Cooperação Sul-Sul (CSS) no campo educacional entre Brasil e Timor-Leste, com base no paradigma do dom e da hospitalidade. Durante o governo Lula (2003-2010), a CSS se constituiu como uma das principais plataformas de inserção do Brasil no meio internacional. Além disso, foi o governo que mais energizou esforços ao desenvolvimento da cooperação educacional. No entanto, o argumento central é que o Brasil ainda necessita investir mais em políticas de recepção de estudantes estrangeiros orientadas por uma lógica do bem-receber. Nesses termos, a metodologia aplicada consistiu na análise de documentos oficiais, incluindo um protocolo de cooperação entre ambos os países, a literatura especializada e uma pesquisa de caráter etnográfico realizada com 30 estudantes timorenses. Diante do que foi observado, conclui-se que o processo de cooperação no campo educacional, quando compreendido a partir de variáveis endógenas e exógenas, revelam peculiaridades e desafios que podem ser superados a partir das práticas ancoradas no paradigma do dom e da hospitalidade.

Palavras-Chave: Cooperação Educacional; Brasil; Timor-Leste; Paradigma do Dom; Paradigma da Hospitalidade.

1 Professora efetiva da Graduação e do Programa de Pós-Graduação em Relações Internacionais da Universidade Estadual da Paraíba (PPGRI/UEPB) e colaboradora no Programa de Pós-Graduação em Antropologia da Universidade Federal da Paraíba (PPGA/UFPB), Mestre e Doutora em Antropologia pelo Museu Nacional da Universidade Federal do Rio de Janeiro (MN/UFRJ), com pós-doutorado no Instituto de Ciências Sociais da Universidade de Lisboa (ICS/ULisboa).

2 Doutorando pelo Programa de Pós-Graduação em Ciência Política da Universidade Federal de Pernambuco (PPGCP/UFPE). Mestre em Relações Internacionais pelo Programa de Pós-Graduação em Relações Internacionais da Universidade Estadual da Paraíba (PPGRI/UEPB). Membro do Grupo de Pesquisa "A Política Externa Brasileira no Conselho de Segurança das Nações Unidas no Pós-Guerra Fria".

Artigo submetido em 26/01/2019 e aprovado em 21/06/2019. 


\begin{abstract}
This article aims to discuss, from the critical perspective, the South-South Cooperation (SSC) process in the educational field between Brazil and East Timor besed on the gift and hospitality paradigm. During the Lula government (2003-2010), the SSC was established as one of the main platforms for insertion of Brazil in the international environment and it was the government that most energized efforts to develop of educational cooperation. However, the central argument considers that Brazil still needs to invest more in reception policies of foreign students guided by a logic of well-being. In these terms, the applied methodology consists of an analysis of official documents, which involves a protocol of cooperation between the two countries, a specialized literature and an ethnographic research with 30 timorese students. In the light of what has been seen, the article concludes that the process of cooperation in the educational field, when understood from endogenous and exogenous variables, reveals peculiarities and challenges that can be overcome by the practices anchored in the paradigm of gift and of hospitality.
\end{abstract}

Keywords: Educational Cooperation; Brazil; East Timor; Paradigm of the Gift; Paradigm of Hospitality.

\title{
Introdução
}

A Cooperação Sul-Sul (CSS) consiste em uma das estratégias de inserção internacional incorporada à agenda política de diversos países. O grau de relevância dado ao tema pelos governos, de acordo com Giacalone (2016), decorreu tanto de uma tentativa de democratizar o sistema multilateral, quanto da necessidade de ampliação do comércio internacional como meio alternativo às fracassadas negociações da Organização Mundial do Comércio (OMC) na rodada de Doha. Assim, conforme a autora, "as interpretações da CSS vão desde o polo da solidariedade até a satisfação dos interesses nacionais dos doadores" (GIACALONE, 2016, p. 143. Tradução nossa) ${ }^{3}$.

O presente artigo trata, justamente, de um tipo de cooperação internacional Sul-Sul, cuja abrangência envolve os interesses nacionais e estratégicos dos partícipes, paralelamente aos referenciais de fortalecimento de vínculos políticos mútuos: a acadêmica e a educacional. Nela, a mobilidade estudantil para fins de capacitação profissional superior fora do seu país de origem opera como um

3 No original: las interpretaciones de la CSS van del polo de la solidaridad al de la satisfacción de los intereses nacionales de los oferentes (GIACALONE, 2016, p. 143). 
meio de estabelecimento de alianças entre Estados, ao mesmo tempo em que pode revelar, nessa relação, valores como os de sensibilidade para com o "outro", senso de responsabilidade e acolhimento.

É justamente nas interrelações que vinculam os indivíduos, nas alianças formadas a partir delas, que o paradigma do dom repousa, sendo o dom, conforme Alain Caillé (2002, p. 19), “o motor e o performador” dessas alianças, uma vez que "as sela, as simboliza, as garante e lhes dá vida". Neste sentido, tendo a cooperação acadêmica firmada entre os governos do Brasil e do Timor-Leste como caso em análise, é possível perceber que interesses na internacionalização das universidades brasileiras e investimento estratégico na CSS, em particular com países lusófonos, por parte do primeiro, e o aprimoramento da língua portuguesa pelos estudantes timorenses, pelo segundo, se entrelaçam no contexto da discussão de tal cooperação à luz do paradigma do dom (MAUSS, 1974; GODBOUT, 1992; CAILLÉ, 2002; SILVA, 2008; REIS, 2016) e da hospitalidade (MONTANDÓN, 2011; NOGUEIRA, 2014). Tendo como principais referências as interpretações que os próprios alunos fazem de suas experiências como intercambistas, a perspectiva adotada é a que articula as conexões entre os níveis internacional (a cooperação acadêmica), dos Estados (Brasil e Timor-Leste) e dos indivíduos (estudantes timorenses).

A análise apóia-se em uma pesquisa que vem sendo executada na Universidade Estadual da Paraíba (UEPB), a partir de 2012, ano em que a instituição recebeu pela primeira vez alunos oriundos do Timor-Leste - 33 no total naquele ano e mais 19, em 2015 -, fruto de um protocolo de cooperação bilateral estabelecido entre o Fundo de Desenvolvimento do Capital Humano (FDCH), da parte timorense, e da UEPB. A investigação, de caráter etnográfico, sofreu uma ampliação entre 2017 e 2018, sendo a ela adicionado o contexto português à problemática, no âmbito de um projeto de pesquisa desenvolvido no Instituto de Ciências Sociais da Universidade de Lisboa (ULisboa), ainda que não seja objeto direto de análise neste artigo. Dessa forma, a etnografia contou com uma amostra de 30 estudantes timorenses, e, além disso, foram tomados como fontes de dados documentos oficiais envolvendo o protocolo de cooperação e a literatura especializada.

A presente análise inicia com uma discussão sobre a CSS e as relações entre Brasil e Timor Leste. Em seguida, trata da cooperação educacional e apresenta dados relativos aos estudantes timorenses no Brasil, bem como analisa a cooperação em sua dimensão cotidiana. E, finalmente, realiza uma discussão da cooperação educacional à luz do paradigma do dom e da hospitalidade. 


\section{A Cooperação Sul-Sul e a Política Externa Brasileira}

A cooperação é um "importante mecanismo de relacionamento entre as nações e como meio de se promover o desenvolvimento humano" (CAIXETA, 2014, p. 17). Dessa forma, logo após a institucionalização da Organização das Nações Unidas (ONU), em 1945, novos desafios emergiram na trajetória dos países em desenvolvimento. Naquele cenário, a necessidade de assegurar o desenvolvimento econômico, em face da retenção de legitimidade das práticas colonialistas, gerou a ampliação das discussões do Sul, com o intuito de promover os interesses nos níveis regionais, trans-regionais e globais (ALDEN; MORPHET; VIEIRA, 2010).

A CSS emergiu no cenário internacional em 1955, a partir da Conferência de Bandung, como fórmula de articulação política a fim de promover o desenvolvimento dos países do Sul (RENZIO et al., 2013). Cabe ressaltar que não há um consenso na literatura a respeito da definição conceitual para a terminologia "cooperação sul-sul” (LEITE, 2012). No entanto, compreende-se que a CSS é "uma estratégia diplomática que se origina de um desejo autêntico de exercer solidariedade para com os países mais pobres. Ao mesmo tempo, ajuda a expandir a participação do Brasil nos assuntos internacionais” (AMORIM, 2010, p. 231, tradução nossa) ${ }^{4}$.

Os dilemas do desenvolvimento econômico e tentativas de solucioná-los foram tema da Conferência do Cairo, no início dos anos 1960, momento em que se institucionalizou a Conferência das Nações Unidas sobre Comércio e Desenvolvimento (UNCTAD) (RENZIO et al., 2013). A conferência foi cenário basilar para mecanismos substanciais que impulsionaram os processos de cooperação do plano Sul Global. Surge, nesse contexto, o Grupo dos 77 (G-77), movimento dos países não alinhados que, no período da Guerra-Fria, se caracterizou como a primeira estratégia de articulação política orquestrada pelos países do Sul. O propósito residia, principalmente, em questionar as regras da política das economias industrializadas, além de reconhecer as assimetrias de poder existentes dentro desse sistema (SANTOS; CERQUEIRA, 2015).

Na década de 1970, a CSS aflorou na agenda das políticas exteriores, tanto de Estados considerados system-affecting - detentores de recursos necessários para agir de forma ativa e afetar determinados temas da política internacional, quanto de países que se apresentavam nos marcos das economias emergentes

4 No original: a diplomatic strategy that originates from an authentic desire to exercise solidarity toward poorer countries. At the same time, it helps expand Brazil's participation in world affairs (AMORIM, 2010, p. 231). 
(SARAIVA, 2007). O posicionamento brasileiro foi marcado, nesse período, pela ênfase na órbita sul-sul e no pragmatismo responsável, praticado no governo Geisel como paradigma político em prol do desenvolvimento econômico (RAMANZINI JR et al, 2015).

A ascensão do capitalismo de mercado como sistema econômico dominante no meio internacional, aliado às ideologias das democracias liberais no mundo pós-Guerra Fria, impulsionaram um movimento direcionado à construção de um ajuste comportamental da parte dos Estados em desenvolvimento em face da nova arquitetura internacional (ALDEN; MORPHY; VIEIRA, 2010). No âmbito das discussões multilaterais, o documento final da Conferência de Nairóbi (2009), aprovado na Assembleia Geral das Nações Unidas (AGNU), apresentou os seis princípios da CSS: respeito à soberania, apropriação nacional e independência, igualdade (horizontalidade), não condicionalidade, não intervenção em assuntos internos e benefício mútuo (BRICS POLICY CENTER, 2017). Entretanto, como sustenta Muñoz (2016), há formas distintas de abordar a CSS, seguindo o debate clássico agente/estrutura. Para o autor:

Uma abordagem crítica implica entrar nesse complexo de relações Estado/ mercado/ sociedade e, com ele, no processo de internacionalização do Estado, na ação transnacional das classes sociais, a divisão internacional do trabalho que supera a separação realista entre o doméstico e o internacional, bem como a sua concepção de Estados como iguais e unitários. (...) a desigualdade não ocorre apenas entre países, mas também entre grupos dentro desses países, que adotam diferentes formas de inserção internacional e solidariedades transnacionais (MUÑOZ, 2016, p. 230-232. Tradução nossa) $)^{5}$.

Ademais, a diversidade que envolve o campo e os atores nele presentes tornam o Sul "uma categoria que tem certa capacidade de atração entre os países em desenvolvimento, sem que implique necessariamente uma unidade absoluta entre eles" (RAMANZINI JR et al., 2015, p. 17). Para Alden, Morphet e Vieira (2010), tal noção atravessa as preocupações dos Estados em distintos campos, seja nas questões de segurança, economia, autonomia e integridade territorial,

5 No original: Una aproximación crítica implica adentrarse en ese complejo de relaciones Estado/mercado/sociedad, y con él en el proceso de internacionalización del Estado, la acción transnacional de las clases sociales, la división internacional del trabajo que supera la separación realista entre lo doméstico y lo internacional, así como su concepción de los Estados como iguales y unitários. (...) la desigualdad no se da sólo entre países, sino también entre grupos al interior de esos países, que adoptan diferentes formas de inserción internacional y de solidaridades transnacionales (MUÑOZ, 2016, p. 230-232). 
ao mesmo tempo em que tecem olhares para as comunidades sulistas e para o estabelecimento de mecanismos congruentes com a defesa da subsistência do mundo em desenvolvimento.

Por isso mesmo, segundo Giacalone (2016), a CSS não é aleatória e, geralmente, está vinculada a modelos de desenvolvimento, estratégias de inserção internacional e de integração regional, que orientam a quantidade e o tipo de recursos a ela destinados. Corroboram com esse pensamento Ramanzini Jr. et al. (2015, p. 14) ao sustentarem que, "para o Brasil, contar com apoio de outros países e criar mecanismos de diálogo e cooperação são questões relevantes para melhorar sua projeção relativa no sistema internacional”. Segundo os autores, os esforços em conjugar os interesses domésticos em benefício do desenvolvimento nacional passam a ter, na relação Sul-Sul, um eixo central de articulação política.

Ao considerar os programas governamentais de inserção internacional do Brasil, Vigevani e Cepaluni (2007) argumentam que, embora se perceba uma mudança ainda durante o governo FHC, é durante o governo Lula que a política externa brasileira enfatiza, com maior teor, a CSS dentro dos propósitos de reduzir os desequilíbrios de poder e aumentar o protagonismo do Brasil no meio internacional. Para Brun (2016), o status de país em desenvolvimento não representa mais uma barreira, passando a ser, simultaneamente, uma justificativa e um instrumento para a atuação externa. Por isto mesmo, defende, que quase todas as diplomacias do tipo Sul-Sul desenvolvem uma política de cooperação.

O objetivo seria, justamente, a aproximação dos parceiros que possuem desafios semelhantes e experiências comuns, voltados para escapar da pobreza a partir da troca de saberes e conhecimentos. Estes incluem colaboração entre instituições e universidades.

\section{O envolvimento do Brasil na questão timorense}

Do quadro das atuações do Brasil no Sul global e das diretrizes políticas quanto aos processos de CSS, é pertinente evidenciar que variáveis conjunturais - como a necessidade de promoção da autodeterminação timorense e o aprofundamento das relações cooperativas - impulsionaram o envolvimento do Estado brasileiro na questão. 
Quando a Indonésia invadiu a região do Timor-Leste ${ }^{6}$, em meados da década de 1970, as posições do Brasil estiveram alinhadas aos posicionamentos contrários à invasora que colocavam o Brasil, em certa medida, num processo de congruência política calcada na defesa de seus princípios consagrados (CUNHA, 2001). Estes princípios, construídos ao longo do pós-Segunda Guerra Mundial, assumiam, naquele momento, a defesa da paz entre as nações, proteção e defesa dos direitos humanos. Cabe dizer que, nesse período, o Brasil, governado por Geisel, tinha como marca uma política externa pragmática e responsável ${ }^{7}$. Assim, a libertação timorense do domínio português e uma busca por maior autonomia após 1975, levou o Brasil a acompanhar a tendência das potências econômicas de voltarem atenção para a Ásia (BRUN, 2016) e, nela, segundo Cunha (2001), para a região do Timor.

O posicionamento brasileiro se pautava pelo desenho da política internacional. Se, por um lado, o país enviou uma missão ao sudeste asiático em abril de 1981, para ampliar o intercâmbio comercial com a Associação de Nações do Sudeste Asiático (ASEAN) - inclusive se interessando pelo "único futuro Estado lusófono asiático" (BRUN, 2016, p. 127) -, por outro, no que tange ao Timor-Leste, procurava não afetar as boas relações com a Indonésia, que ocupava aquele território, acompanhando assim, "a evolução da situação".

Contudo, nota-se que, a partir do final dos anos 1980, como salientado por Brun (2016), ocorre um declínio desse primeiro impulso de CSS, devido a uma retração geral no relacionamento dos países em desenvolvimento, em grande medida decorrente de endividamentos frente às potências mundiais. A diplomacia, no começo dos anos 1990, ainda seguiria retraída devido a esse contexto.

Diante de mudanças conjunturais para o pós-Guerra Fria, alterações domésticas e internacionais influenciaram o posicionamento brasileiro. Na configuração desses novos formatos, o processo de redemocratização brasileiro, em 1988, aliado ao aprofundamento das relações com Portugal e dos princípios compartilhados entre as duas nações, a questão do Timor-Leste adquiriu maior relevância por parte da diplomacia brasileira, embora ainda não constituísse assunto prioritário (CUNHA, 2001; BRUN, 2016).

Da ocupação indonésia (1975) à interferência da ONU no país por meio da

6 Timor-Leste passou por diversos regimes políticos e dominações ao longo de sua história. Foi colônia portuguesa por mais de 400 anos, ocupada pela Indonésia por mais de 20 anos, recebeu missões de paz e apenas realizou sua primeira eleição presidencial em 2002 (ver Durand (2009)).

7 Para melhor entendimento da política externa em Geisel, ver Oliveira (2005) e Mendonça e Myamoto (2011). 
Interfet (com a qual o governo brasileiro contribuiu, entre 1993 e 1997), o Brasil evitou confrontar diretamente o governo indonésio, membro da ASEAN, seguindo, assim, Portugal, Angola, Cabo Verde, Guiné-Bissau e Moçambique (BRUN, 2016). Embora registre-se que, a partir do momento em que o Brasil assumiu a defesa dos direitos humanos, claro no discurso do presidente Fernando Collor à Anistia Internacional, o país passaria a endossar a defesa desse princípio denunciando as violações cometidas pela Indonésia (CUNHA, 2001).

Nesse processo de transição conjuntural, o Brasil voltou sua atenção para os países lusófonos e o Atlântico Sul. Conforme Brun (2016, p. 157), depois da primeira Cúpula dos Países de Língua Portuguesa (1989), realizada em São Luiz do Maranhão (Nordeste do Brasil) por iniciativa do governo José Sarney (1985-1990), e com o lançamento do Instituto Internacional de Língua Portuguesa, os laços entre esses Estados se intensificaram, resultando, assim, na criação da Comunidade dos Países de Língua Portuguesa (CPLP), em 1996.

O governo Itamar Franco (1992-1995) colocou a Ásia como uma das regiões de importância, postura também adotada por FHC (1995-2003). Em 1997, o MERCOSUL e a ASEAN iniciaram um diálogo. No campo bilateral, os governos brasileiros assinaram parcerias acadêmicas com seus homólogos na Malásia, Singapura e Tailândia, mas enfatizou especialmente a África.

No segundo lustro da década de 1990, a diplomacia brasileira se envolveu, em maior grau, com a problemática timorense, em decorrência dos trabalhos desenvolvidos por Kofi Annan, então Secretário Geral da ONU. Observemos em suas palavras: "quando assumi o cargo, em 1997, pus o caso do Timor-Leste na lista das negociações diplomáticas emperradas às quais eu pretendia dar um novo impulso" (ANNAN, 2013, p. 133).

Depois do término da dominação provocada pela Indonésia sobre TimorLeste e das perturbações sociais e saques promovidos pelas milícias a favor da Indonésia, o Estado brasileiro, por meio da Agência Brasileira de Cooperação $(\mathrm{ABC})$, colocou-se de forma presente naquele país, assumindo o propósito de apoiar a atividade internacional para a construção da paz do mais recente Estado do sistema internacioal (AGÊNCIA BRASILEIRA DE COOPERAÇÃO , 2012).

No que se refere à defesa da comunidade internacional para a proteção dos direitos humanos, se considerarmos um recorte temporal do início do pós-Guerra Fria até os atentados nos Estados Unidos, em setembro de 2001, o Timor-Leste foi um dos fenômenos que mais mobilizaram as relações internacionais, como sustentam Pepe e Mathias (2006). 
Durante visita oficial ao Timor-Leste, em 2001, FHC enfatizou os processos de cooperação educacionais desenvolvidos entre o Brasil e o país asiático, dentre os quais destacou "o combate ao analfabetismo, o treinamento de professores, a formação profissional” (FHC, 2001, p. 33). Dentro desse espectro, Soares (2016) enfatiza que os estreitos laços entre o Brasil e o Timor-Leste são caracterizados por vínculos culturais e institucionais oriundos do legado lusófono, na medida em que considera o Timor como a única nação asiática a adotar o idioma português na qualidade de sua língua oficial e, do ponto de vista institucional, conjuntamente com o Brasil, compartilha a mesma arena de discussão na CPLP.

As missões de paz da ONU no Timor Leste proporcionaram ao Brasil a oportunidade de se envolver, enfaticamente, no processo de construção da paz timorense, calcando-se numa propositura holística e de longo prazo (BRACEY, 2011). De maneira específica, observa-se, em 2008, quando em visita à capital do Timor-Leste, Díli, o então presidente Lula ressaltou que os compromissos assumidos pelo Estado Brasileiro envolveram tanto o plano multilateral, contribuindo com o processo de construção da paz por meio da ONU, como o plano bilateral, enfatizando os processos cooperativos do Brasil com o Estado timorense em diversas áreas, com destaque para os campos de segurança, justiça e educação (LULA DA SILVA, 2008).

\section{A Cooperação Educacional entre Brasil e Timor-Leste}

O governo Lula da Silva (2003-2010) foi o que conferiu maior proeminência à cooperação educacional internacional. No nível doméstico, ocorreu um incentivo à internacionalização acadêmica das Instituições de Ensino Superior (IES), conforme Sebastián (2004), e à Cooperação Universitária para o Desenvolvimento (CUD), em Zanesco e Salomón (2013). Segundo o Ministério das Relações Exteriores (BRASIL, 2015), esses tipos de cooperação possibilitam à política externa brasileira agir em ao menos três frentes: 1) econômica, "ao relacionar-se diretamente à qualificação da mãodeobra (sic) de um país”, interferindo no desenvolvimento econômico do mesmo e em uma melhor inserção no mercado internacional; 2) política, promovendo a "aproximação entre os estados por meio dos seus nacionais", a partir de princípios de "solidariedade e respeito"; 3) cultural, com o estreitamento de laços baseados em valores compartilhados de "tolerância" e "compreensão mútua", produzidos na "convivência", no "aprendizado do idioma" e na "troca de 
experiências" (BARROS; NOGUEIRA, 2015). Trata-se, portanto, de uma importante ferramenta de soft power.

De acordo com Milani, Conceição e M’Bunde (2016), ainda que a cooperação técnica não seja uma prioridade no que tange as despesas públicas $-6,3 \%$ do orçamento total da Cooperação Internacional para o Desenvolvimento (CID) de 2010, 57.770.554 milhões de dólares (MILANI; CONCEIÇÃO; M’BUNDE, 2016, p. 16) -, "a educação está entre os três setores mais relevantes dos programas de cooperação técnica do Brasil, ao lado de saúde e agricultura” (p. 17), com foco nos países em desenvolvimento da América Latina, Caribe, África e Timor-Leste. A distribuição de bolsa de estudo para estrangeiros dentro da cooperação educacional, contemplada pela $\mathrm{ABC}$, tem como objetivos: “(i) promover maiores padrões de educação de cidadãos oriundos de outras regiões em desenvolvimento; (ii) promover diálogo no domínio da educação entre jovens brasileiros e estrangeiros; e (iii) divulgar a cultura e a língua brasileira” (MILANI; CONCEIÇÃO; M’BUNDE, 2016, p. 17).

Como lembram Burgues (2014) e Reis (2016), a concessão de bolsas de estudo e a implementação de programas de mobilidade acadêmica "produzem o efeito de difundir práticas e valores promovidos pelo país doador, ampliando o seu soft Power" no âmbito dos Estados partícipes de tais projetos e no contexto do Sul Global (REIS, 2016).

Criado oficialmente em 1965, o Programa Estudante Convênio de Graduação (PEC-G) insere-se nesse tipo de política, ao oferecer a alunos de países em desenvolvimento com os quais o Brasil mantém acordo educacional, cultural ou científico-tecnológico a oportunidade de realizar os estudos de graduação em uma Instituição de Ensino Superior, IES, nacional. Do mesmo modo funciona o PEC-PG, de pós-graduação, criado em 1981. Ambos são administrados pela Divisão de Temas Educacionais (DCE), do MRE, e pelo Ministério da Educação (MEC) ${ }^{8}$, em parceria com as instituições, e concedem bolsas de estudos para os alunos selecionados.

O quadro brasileiro no tocante às Instituições de Ensino Superior torna-se um atrativo para países do Sul Global, incluindo Timor-Leste. Somente relativo a universidades públicas federais, são mais de 60. O Instituto Nacional de Estudos e Pesquisas Anísio Teixeira (INEP), no seu Censo da Educação Superior de 2010, mostra que há um total de 2.377 IES (278 públicas e 2.099 privadas) (BARROS;

8 No caso do PEC-PG, além do MRE e do MEC (por meio da Coordenação de Aperfeiçoamento de Pessoal de Nível Superior, Capes), também administra o Programa o Ministério da Ciência, Tecnologia, Inovações e Comunicações (MCTIC), por meio do Conselho Nacional para Desenvolvimento Científico e Tecnológico (CNPq), a quem cabe a seleção e o pagamento das bolsas de mestrado para estudantes de todos os países participantes, com exceção de Timor-Leste, sob responsabilidade da Capes. 
NOGUEIRA, 2015). Além da quantidade de IES, a qualidade de uma parte significativa dos cursos e o próprio idioma português, com que se ministram as aulas, constitutem fatores de atração para os estudantes e, antes, para estratégia governamental timorense.

Diferentemente do Brasil, no caso do Timor-Leste, as sucessivas políticas de educação e interferências externas (colonização portuguesa, invasão indonésia, missões da ONU, etc.) geraram um quadro de deficiência na área educacional ${ }^{9}$ em geral. De acordo com Silva (2015), o nível muito baixo de literacia colocou para o governo e a sociedade civil o enorme desafio de erradicar totalmente o analfabetismo em Timor-Leste. A implementação da política linguística, tendo Tétum e Português como línguas oficiais, é um dos principais desafios, uma vez que a diversidade de políticas educacionais de acordo com a nacionalidade dos governos e a própria variedade de línguas maternas originais resultaram no fenômeno de uma pequena minoria que domina o Português, em especial em gerações mais novas, que nasceram e se educaram em línguas indonésias.

A construção de uma cultura baseada na educação formal tende a aumentar, conforme dados do Timor-Leste 2010 Population and Housing Census - Series of Analytical Reports. Vol. $9^{10}$ (RDTL, 2012): o letramento de jovens (15 a 24 anos) é significativamente alto (79.1\%) em relação ao de adultos (57.8 \%), um sinal de que vem ocorrendo um aperfeiçoamento na área de educação no país. Menos de um em 10 jovens entre 18 e 23 anos estuda em nível superior; cerca de metade (44\%) desses, a partir dos 25 anos. Cerca de 4.290 obtiveram, na universidade, o grau de mestre ou qualificação acima disso, sendo que $62 \%$ são homens e $38 \%$ mulheres (p. vii). No Timor Leste, de um total de 343.187 pessoas que estudavam em 2010, somente 5,1\% estavam no nível superior (4,6\% na universidade e $0,5 \%$ no politécnico/diploma); eram aproximadamente 18 mil pessoas, das quais 15.898 estavam na universidade, sendo a maioria residente na capital Díli e com mais de 30 anos (p. 22-23; 25). Cabe dizer que a única universidade pública no Timor-Leste é a UNTL (Universidade Nacional Timor Lorosa'e), fundada em 2000, integrando a Associação de Universidades de Língua Portuguesa (AULP), a Rede de Instituições Públicas de Ensino Superior (RIPES) e a Indonesia Timor-Leste

9 Uma das primeiras ações implementadas dentro da cooperação educacional brasileira com Timor-Leste foi o Programa de Qualificação de Docentes e Ensino de Língua Portuguesa (PQLP), uma colaboração entre o governo timorense e a CAPES, em que foram enviados professores para qualificar docentes lá. Como foge à proposta deste artigo, não será contemplado.

10 Censo de População e Habitação - Série de Relatórios Analíticos (tradução livre). 
Australia Academic Partnership, envolvendo cinco universidades do Timor-Leste, cinco da Indonésia e uma da Autrália (UNTL, 2017).

A combinação, portanto, de o Brasil ter se constituído como um país lusófono atrativo para Timor-Leste em um contexto das relações do Sul-Global (por sua estrutura acadêmica), com o processo de construção do Estado timorense (ainda deficitário no campo da Educação), resultou no fato apontado por Pereira, Cassiani e Linsingen (2015), de que, em 2013, havia nas universidades brasileiras um total de 150 estudantes timorenses. Para os autores, isso foi resultado também de uma política de internacionalização das próprias universidades brasileiras.

Especificamente, quanto à internacionalização das universidades, Sebastián (2004) ressalta que ela ultrapassa o âmbito das instituições acadêmicas, influenciando em políticas educativas que se misturam a diversas motivações (econômicas, culturais, etc.). Para ele, a mobilidade internacional de estudantes impacta sobre o processo de incorporação cultural da própria internacionalização, afetando mentalidades, valores e percepções. Já em relação à cooperação internacional, o autor enfatiza como fundamentos, objetivos ou impactos, o aumento e a transferência do conhecimento científico e tecnológico, a criação de capacidades, o desenvolvimento institucional e a contribuição para o desenvolvimento humano, social e produtivo.

Brun (2016), Pereira, Cassiani e Linsingen (2015), Butcher et al. (2015), Nogueira (2014), Carey (2003) e Silva (2008), chamam a atenção, de uma forma crítica, para as dificuldades que envolvem o estabelecimento de relações horizontais na CSS ou nos processos de internacionalização de universidades. Particularmente, tendo as reuniões de doação e ajuda internacional para o desenvolvimento (AID) do Timor-Leste como foco de estudo etnográfico, Silva (2008) ressalta que, contratados pelas Nações Unidas e por agências bilaterais de cooperação, assessores dos mais diferentes países - Portugal, Austrália, Brasil, Índia, Paquistão, Sri Lanka, Irlanda, Espanha, Equador, Filipinas, Nova Zelândia, África do Sul, Jamaica, Estados Unidos e outros - para trabalharem diretamente na formação do Estado timorense tendiam “a reproduzir in loco os princípios de fundação e gestão da máquina pública existentes em seu país de origem ou naqueles em que adquiriu sua maior capacitação profissional”.

A autora aponta ainda que poucos foram os técnicos estrangeiros que se dispuseram a aprender o Tétum, língua de comunicação local, idioma oficial, que possibilita o diálogo entre os timorenses versados em línguas maternas particulares. Português e inglês eram os idiomas de comunicação entre eles com os locais em 
capacitação. Conforme exemplifica Silva (2008, p. 161), "funcionários públicos timorenses - direta ou indiretamente subordinados a um assessor australiano que trabalha em língua inglesa [...] - provavelmente estarão lidando com rotinas de gestão da administração pública típicas de um sistema de Common Law”; já no contato com assessores lusófonos, os servidores timorenses "tenderiam a utilizar a língua portuguesa e a reproduzir rotinas administrativas típicas”.

Essas práticas levam a autora a concluir que esses casos "indicam como práticas de assistência técnica internacional operam como instrumentos políticos nos processos de formação de identidades estatais em países de independência recente", constituindo-se "palco para disputas entre diferentes projetos civilizatórios existentes entre diferentes agentes do campo da AID” (SILVA, 2008, p. 162). Entre os internacionais, Silva aponta, as disputas polarizam-se principalmente entre projetos anglófonos e lusófonos para a construção do Estado.

Ao recuperar o turbulento passado histórico do Timor-Leste, Butcher et al. (2015, p. 21) ressaltam que o povo não foi “mestre em seu próprio país”, configurando uma situação de colonialidade do poder (MIGNOLO, 2003), que transforma diferenças de localidades em valores, tendo como referência o modelo colonial europeu - caso do próprio Timor-Leste e do papel exercido pelo Brasil dentro desse contexto apresentado, como destacam criticamente Pereira, Cassiani e Linsingen (2015).

Nessa direção, tais autores inserem a discussão em um contexto mundial, ressaltando a existência de uma agenda em educação globalmente estruturada, que repercute no próprio trabalho em sala de aula do professor. Este, direcionado pelo senso de cooperação internacional, transmite conteúdos eurocentricamente orientados e legitimados pela agenda. Dessa forma, o que a presente pesquisa junto aos estudantes revela é que, precisamente, aí residem todas as dificuldades apontadas por eles no que se refere à língua, aos conteúdos e à relação professor-aluno em sala de aula, na dimensão cotidiana da cooperação, como será discutido em seguida.

\section{Estudantes timorenses no Brasil e na UEPB}

Em um panorama geral, ao lado do continente africano, Timor-Leste é o que mais tem firmado convênios acadêmicos com o Brasil. No que diz respeito à cooperação educacional, Barros e Nogueira (2015) ressaltam que o país é o que possui maior número de estudantes entre os sete países asiáticos que participam 
do PEC-G. Especificamente no que diz respeito aos estudantes timorenses, o gráfico 1, a seguir, ilustra a distribuição temporal de tais alunos entre $2006 \mathrm{e}$ 2019, totalizando 73 selecionados para cursos de graduação.

\section{Gráfico 1 - PEC-G Candidatos Selecionados do Timor-Leste, 2006-2019}

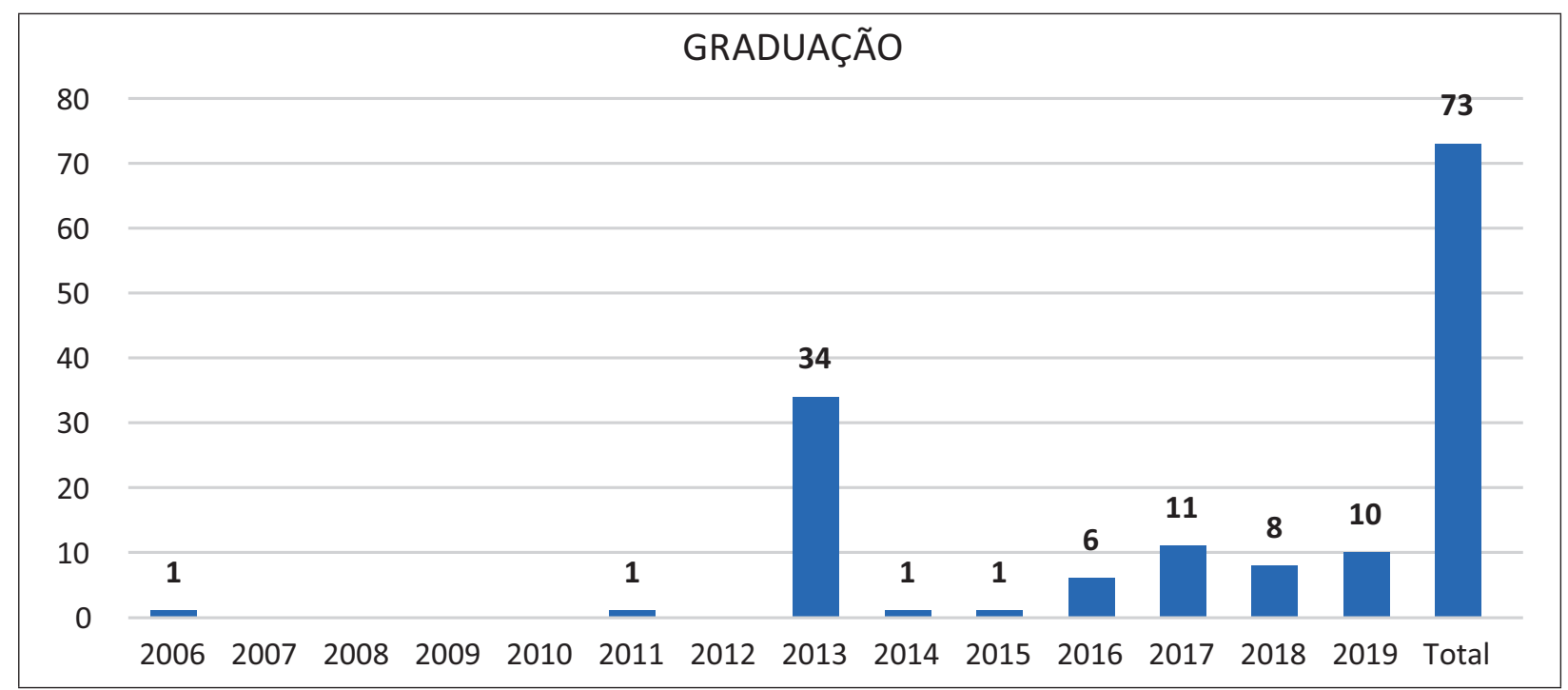

Fonte: Elaborado pelos autores com base nos dados da DCE/MRE (2019 a).

No que se refere ao PEC-PG, o Timor-Leste foi o país asiático que mais teve estudantes selecionados. Segundo dados do DCE/MRE, 2005 foi o primeiro ano em que o país participou do Programa, com seis alunos (DCE/MRE, 2019b). Em 2006, nenhum estudante foi selecionado, porém a partir de 2007 houve seleções consecutivas, como mostra o gráfico 2.

Gráfico 2 - PEC-PG Candidatos Selecionados do Timor-Leste, 2005-2019

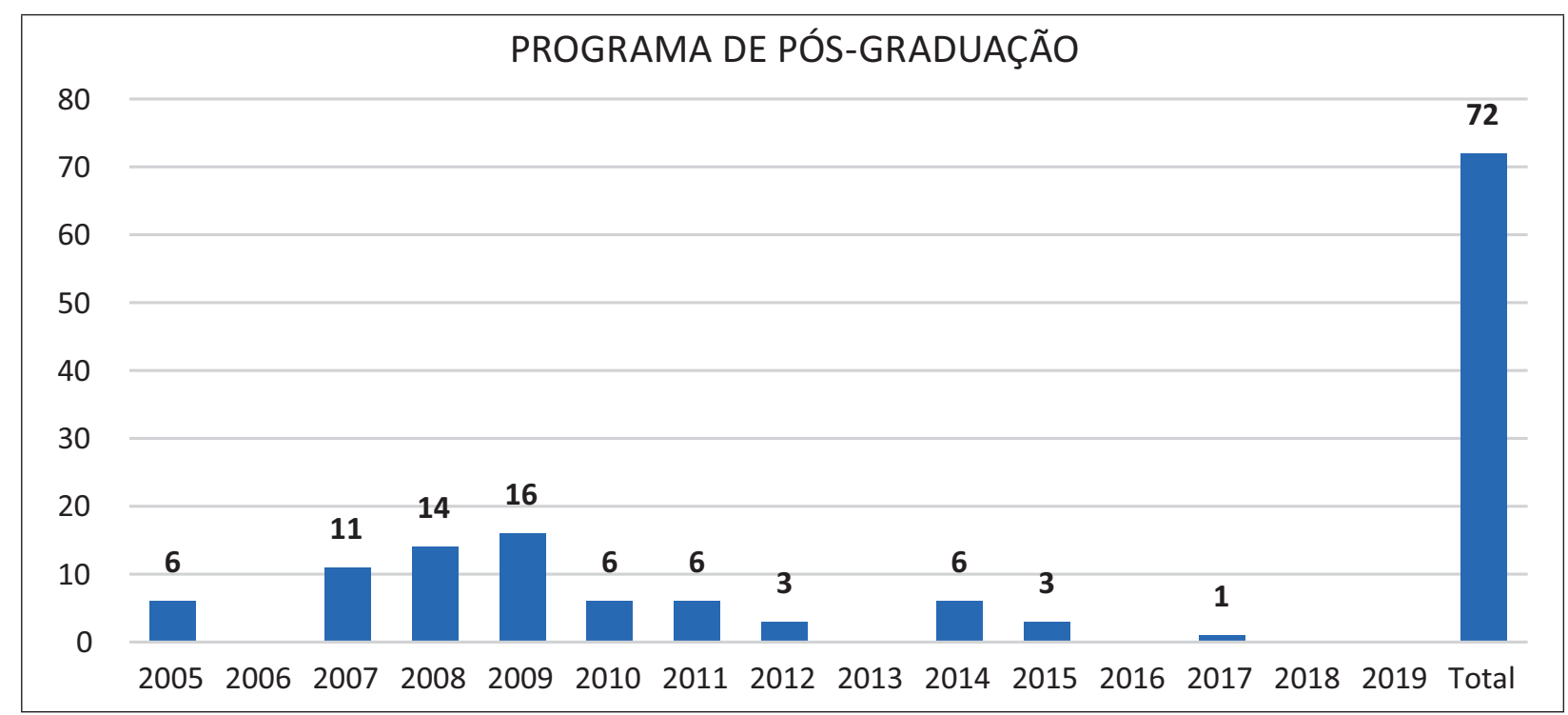

Fonte: Elaborado pelos autores com base nos dados da DCE/MRE (2019b). 
Em referência ao Gráfico 2, não se pode esquecer que, em 2011, foi criado o Fundo de Desenvolvimento do Capital Humano pelo governo do Timor-Leste. A partir de 2012, o fundo passou a financiar bolsas de estudo para timorenses no exterior, o que provavelmente explica a diminuição da participação no PEC-PG, particularmente mais voltado para aqueles que já desempenhavam ou que viriam a desempenhar alguma função pública nos quadros governamentais do país e que necessitam tanto de capacitação profissional quanto de domínio da língua portuguesa. Como ressaltado por Reis (2016),

Em relação ao Timor-Leste, os programas de mobilidade de discentes para o Brasil têm como consequência a formação de futuros profissionais que atuarão no âmbito do setor público daquele país, com a capacidade de desenvolver e implementar políticas favoráveis à atuação dos interesses brasileiros na região. Cabe destacar, por exemplo, que o Brasil, por meio do Instituto Rio Branco, oferece vagas para que os diplomatas timorenses sejam capacitados nos mesmos cursos de formação destinados aos diplomatas brasileiros, assim, os profissionais do Timor-Leste têm a oportunidade de entrar em contato direto com os valores do corpo diplomático nacional, com a história, com a cultura e com o próprio povo brasileiros (LAMAZIÈRE, 2012, p. 87 apud REIS, 2016, p. 141).

Frequentar universidades em países lusófonos configura uma estratégia para conquista desse duplo objetivo de formação de quadros e de fortalecimento de uma língua oficial ainda pouco desenvolvida no Timor-Leste. Lembre-se que a "Ilha do Crocodilo" vem passando por um processo de state-building e nationbuilding ${ }^{11}$ desde a restauração da independência, em 2002.

Paralelamente à participação no PEC-G e no PEC-PG, protocolos específicos de cooperação foram estabelecidos pelo governo timorense com a Unilab e a UEPB. Em 2012, em protocolos particulares, a Universidade da Integração da Lusofonia Afro-Brasileira foi a que mais recebeu estudantes timorenses, com um total de 72 estudantes, seguido pela Universidade Estadual da Paraíba, com 33 alunos, em cursos de graduação e pós-graduação (UEPB, 2013).

Quanto à Unilab, o intercâmbio de estudantes é efetivado por todos os países participantes da CPLP, não apenas os Países Africanos de Língua Oficial Portuguesa (PALOP). Assim, no caso do Timor-Leste, conforme dados disponíveis em junho de 2017 no site da Unilab, há 69 timorenses nos cursos de graduação, sendo que,

11 Construção de Estado e Construção de Nação, respectivamente (tradução livre). 
no âmbito dos países lusófonos, fica atrás de Guiné-Bissau (562 estudantes), Angola (118), Cabo Verde (95), São Tomé e Príncipe (86), mas à frente de Moçambique (31). O processo de seleção dos candidatos estrangeiros, realizado no próprio país de origem do pretendente, constitui-se de uma avaliação do histórico escolar do Ensino Médio e de uma prova de redação, sendo que os interessados se inscrevem nas Missões Diplomáticas brasileiras presentes nos seus respectivos países.

À Universidade Estadual da Paraíba chegaram, em 2012, uma primeira leva de alunos para cursar graduações e pós-graduações distintas. A recepção desses estudantes ocorreu dentro de um protocolo de cooperação bilateral firmado em 2011 entre a universidade e o FDCH. Na ocasião, chegaram à universidade três estudantes para o mestrado em Formação de Professores, dois, respectivamente no de Saúde Pública, de Ensino de Ciência e Matemática e de Desenvolvimento Regional, além de Ciências Farmacêuticas e Farmácia, com um aluno em cada. No nível de Graduação, os cursos mais procurados foram: Informática, com seis estudantes; Relações Internacionais, 5, sendo que, posteriormente, um deles se tranferiu para o Direito; Direito, 5; Odontologia, 4 e Contabilidade, 2. As áreas foram predeterminadas pelo governo timorense, que financiou bolsas de estudos para todos, no valor, à época, equivalente a 750 dólares mensais, ainda que inicialmente pagos de modo acumulado a cada seis meses (depois passaram a ser mensais, ainda que com atrasos) ${ }^{12}$.

Dentro do protocolo estabelecido, foi condicionada a previsão de um "Semestre Zero"13, em que foram ofertados cursos de Português e Matemática pela universidade para fins de nivelamento, antes do início dos cursos profissionais propriamente ditos. Especificamente, a falta de domínio da língua portuguesa foi o principal problema apontado pela quase totalidade dos 30 interlocutores da pesquisa, de caráter etnográfico.

Como disse um aluno de graduação ${ }^{14}$ - expressando o conjunto deles -, mesmo com o "Semestre Zero", a iniciativa "não foi suficiente para nos comunicarmos, para entendermos os conteúdos das disciplinas”. Acrescente-se a isso, a percepção

12 Um agradecimento especial à Coordenação de Relações Internacionais e Institucionais da UEPB pelo fornecimento dos dados, e ao adido do Timor-Leste no Brasil, à época, pelas informações sobre as bolsas.

13 Foi justamente ao final do "Semestre Zero" que um dos autores deste trabalho, Nogueira, estabeleceu os primeiros contatos com os estudantes timorenses da pesquisa. Porém a etnografia junto a eles passou a ser desenvolvida sistematicamente a partir de 2013.

14 Para garantia do compromisso de anonimato e proteção das fontes, assumido junto aos estudantes, estes não serão identificados. 
dos estudantes de que não falar o Português também "piorou a compreensão da cultura brasileira, muito diferente da que tínhamos em Timor", conforme outra aluna de mestrado, por terem "visões de mundo muito diferentes", complementa outro aluno de graduação. A falta de entendimento do Português, desse modo, foi apontada como problema para a capacitação e a integração cultural desses estudandes, em particular no primeiro ano de curso.

Na sala de aula, atividades como leituras específicas ou apresentação de seminários constituem-se verdadeiros pesadelos para os estudantes. Além da dificuldade com a língua em si, os significados de alguns conceitos - por exemplo, o de democracia brasileira apoiada em um sistema político de equilíbrio entre os poderes Executivo, Legislativo e Judiciário - levou um estudante de Relações Internacionais a pedir a um de nós que o levasse para conhecer a prefeitura e a sede do governo estadual, as câmaras estadual e municipal e os tribunais de Justiça paraibanos. Outro, muito preocupado, solicitou uma conversa sobre a possibilidade de volta de ditadura militar, com militares armados na rua, no processo de Impeachment da presidente Dilma Roussef, pois escutava dos colegas que estava ocorrendo um "golpe", o que o levava imediatamente a tecer uma relação com a violenta invasão indonésia no Timor-Leste. Com base na pesquisa etnográfica, pode-se perceber que os alunos dos cursos das áreas das ciências humanas e sociais possuíam mais dificuldades do que aqueles cursando as áreas de ciências exatas.

Como dito, a sala de aula e a apresentação de seminário em grupo também foram apontados como nevrálgicos: alguns estudantes contaram que nunca eram escolhidos por estudantes brasileiros para formarem grupos - o que eles atribuíam às dificuldades iniciais com a língua, que poderiam prejudicar a nota do grupo - e a própria relação professor-aluno era "complicada", segundo um deles. Isso porque, conforme relatos de um aluno e uma aluna, "nas escolas públicas no Timor, em algumas delas, até pouco tempo eram comuns castigos". Muito constrangida, uma aluna de graduação explicou porque, no início, não tiravam dúvidas ou abordavam o professor: "tenho medo; medo e respeito".

Outro problema apontado pelos estudantes foi a não compreensão do funcionamento do sistema acadêmico brasileiro. Ao lado dele, outra dificuldade para alguns deles - em especial os mais jovens - foi ter que lidar com os gastos da bolsa (pagar aluguel, fazer compras de comida, etc,) dentro de um orçamento doméstico. Vários deles nunca tiveram que se preocupar com isso, por nunca terem saído de perto de seus pais (responsáveis por essas tarefas no Timor-Leste). 
Tais dificuldades são apontadas em períodos iniciais dos cursos. Ao longo do tempo, particularmente a partir do segundo ano, no caso da graduação, e na parte final da pós-graduação, os alunos apresentam-se mais confortáveis com a língua, a cultura local e com o próprio sistema acadêmico. Ademais, a rede formada por estudantes nas universidades brasileiras (incluindo a UEPB) e as informações nelas compatilhadas foram fundamentais pontos de apoio para os que chegaram após essa primeira turma, em 2012. Este foi o caso dos 19 timorenses que chegaram à Universidade Estadual da Paraíba em 2015 (UEPB, 2015).

Tendo em vista os depoimentos dos estudantes timorenses à luz de uma visão crítica sobre a cooperação de tipo Sul-Sul na qual estão inseridos - em que se pode enxergar a presença eventual de uma verticalidade, caracterísitca das cooperações do tipo Norte-Sul, como uma lógica oculta em algumas inicativas desse tipo de cooperação -, pode-se perguntar: como tornar mais horizontal a cooperação educacional no Sul Global, de modo que gere desenvolvimento para todos os parceiros envolvidos? A proposta aqui apresentada é que a cooperação educacional e a internacionalização das universidades no Brasil sejam orientadas pelo paradigma do dom e da hospitalidade.

\section{O Paradigma do Dom e da Hospitalidade}

Olhar mais de perto para a cooperação educacional internacional, a partir das vivências diárias dos estudantes em um país distinto do dele, coloca importantes desafios para os governos (do local de origem e de destino), as instituições e os indivíduos nela envolvidos. Um dos mais relevantes diz respeito à forma como são recebidos. Outro, aos choques culturais pelos quais passam e que muitas vezes dificultam a integração e o savoir faire necessário para que possam se adaptar à realidade local, ao sistema acadêmico, à nova vida em geral.

Ultrapassando a frieza burocrática de um protocolo diplomático assinado, é preciso lembrar que se trata de um conjunto de jovens (em sua maioria), que se desloca em função de capacitação profissional e em busca de um futuro melhor, particularmente no caso de alunos de países do Sul Global. Nesse sentido, quando falamos de cooperação, falamos de interação entre pessoas, de vínculos criados - entre Estados e instituições, certamente e, sobretudo, entre pessoas.

Analisar a cooperação internacional na área da educação como uma construção diária implica não deixar de fora a noção de hospitalidade e do bem-receber. 
O foco no nível dos indivíduos ressalta a dimensão dos vínculos criados e mantidos na situação da cooperação. Esta, entendida sob a ótica da troca, da dádiva/dom, possibilita adicionar humanização às decisões políticas tomadas, indo além de vontades de exercer soft power e atender a interesses egoístas dos Estados.

Como apontado por Silva (2008), que ressalta a dimensão da dádiva (dom) presente nos projetos de AID, neles ocorre uma supervalorização do papel do doador internacional, engendrando as tentativas de "construção de hegemonia" (SILVA, 2008, p. 164), pois "as dádivas ofertadas pelos doadores enlaçam Timor-Leste [...] em relações de obrigação, que se manifestam em espaços globais de negociação política, como a Assembléia Geral da ONU” (SILVA, 2008, p. 165) e aumenta capacidade dos doadores de "exercer influência sobre a condução da política interna" do país. A autora ressalta, portanto, que a "economia da dádiva" opera em muitos níveis, ultrapassando a função de gestão de relações políticas.

Compreender a cooperação internacional como dádiva (REIS, 2016; NOGUEIRA, 2014; SILVA, 2008; CAILLÈ, 2002) demanda mobilizar pressupostos apoiados em Mauss (1974), quanto à teoria das trocas sociais: o ato de troca contém três ações (dar, receber, retribuir); as coletividades nelas envolvidas se obrigam mutuamente e estabelecem contratos entre si; retribuir é um ato simultaneamente voluntário e obrigatório; trocar ajuda a definir quem são os amigos e os inimigos, com base nos vínculos e alianças criadas; as dádivas/dons sempre carregam algo do doador, ultrapassando seu valor utilitário.

É preciso, portanto, definir quem são os parceiros da troca, o que eles trocam (as dádivas/dons) e em qual situação. O que se troca pode ser bens materiais e/ou imateriais (gentilezas, amabilidades, etc.), conforme Mauss (1974). Mas segundo Godbout (1992), a dádiva, o dom, não é gratuito, nem poderia sê-lo, pois é a dívida e a expectativa de pagá-la que possibilita a relação. Assim, a situação da troca implica que alguém doe (doador) algo (dádiva/dom) para alguém (receptor), que precisa aceitar o que foi doado e, se quiser manter a relação, precisa retribuir o que recebeu. O tempo para isso varia conforme entendimento dos parceiros da troca. É justamente o processo espiralizado de doações, recepções, dívidas e retribuições que alimentam o vínculo, a relação entre os parceiros. Como destaca Caillé (2002, p. 8), o laço social "é mais importante que o bem, eis o que o dom afirma”.

Especificamente no que concerne à Cooperação entre o Brasil e o Timor-Leste, Reis defende que: 
(...) é uma dinâmica de contraprestações que envolve não apenas os valores, crenças e ideias relacionados a essas nações, mas também aos aspectos morais relacionados à cooperação internacional, à CSS, à comunidade de países lusófonos, às diversas agências, secretarias e ministérios envolvidos ao longo do processo coperativo (REIS, 2016, p. 119).

Para os estudantes timorenses, a capacitação profissional/acadêmica e o aprendizado do português são as principais dádivas recebidas das universidades brasileiras em que estudam. Essa visão é compartilhada pela maioria dos alunos que se encontram em fase de finalização de seus cursos. A distinção social (BOURDIEU, 2007) por terem estudado fora na ocasião do retorno também é dádiva ${ }^{15}$. Para as universidades, a dádiva são a internacionalização, a construção de reputação acadêmica em nível mundial e uma classificação favorável em rankings de IES no país pelo MEC e agências de fomento. Para o Estado brasileiro, o dom é o fortalecimento de sua política externa voltada para a CSS, o reforço na multilateralidade política, com a diversificação de parceiros (na lógica da dádiva, alianças para fazer “amigos”) e a construção de reputação internacional como "doador", que age com referenciais de solidariedade para com os (quase?) iguais. As dádivas do governo timorense são a formação de quadros para a construção do Estado, o reforço na política lingüística oficial e no campo da Educação no nível interno.

Por tudo isso, a recepção de estudantes do Timor-Leste pelo Brasil não é simples. Desse modo, se a dádiva/dom sempre carrega algo do doador, no caso da CSS entre Brasil e Timor-Leste, ela é a da hospitalidade. Para Perrot (2011), a “dádiva da hospitalidade” coloca questões diretamente relacionadas às noções de identidade de doadores e receptores, "a daquele que, dando, dá algo de si e, talvez mais ainda, a daquele que, recebendo, acolhe algo do outro" (PERROT, 2011, p. 64). Como já explorado em outro lugar,

(...) o vínculo que cria da dádiva, vínculo de "pessoa a pessoa” é antes de tudo uma brecha aberta na identidade, hospitalidade a um outro no próprio sujeito. Daí a reversibilidade tão espantosa do vocabulário: aquele que dá (a hospitalidade) recebe (o outro), e aquele que é recebido (no caso do outro) lhe dá (de si mesmo). Dessa renúncia ao recolhimento identitário "egoísta” nasce o sentimento de um comum pertencimento (NOGUEIRA, 2014, p. 118).

15 Há uma recorrência nos depoimentos dos alunos do Timor-Leste no Brasil e em Portugal, ao longo da pesquisa, de que são identificados como distintos, “de elite”, por terem estudado fora e dominarem a língua portuguesa, elemento de distinção em um país que, embora tenha o Português como língua oficial, poucas são as pessoas que a dominam (sobre a questão do Português, ver Bartoréo (2009)). 
Nesse sentido, praticar a hospitalidade é "fazer uma dádiva de si” (MONTANDÓN, 2011, p. 43).

Retornando à análise da cooperação educacional do Brasil com o Timor-Leste no nível cotidiano, constata-se que as dificuldades com a língua portuguesa, com tradições e hábitos culturais muito distintos, com o sistema acadêmico, com o manejo das bolsas de estudo - os valores mensais, em torno de 750 dólares pelo governo timorense, pagos acumuladamente a cada seis meses -, além da própria inexperiência de parte dos alunos que possuem idade entre 18 e 23 anos, desafia o país e as universidades na arte do bem-receber e da hospitalidade.

Como já assumido por Sebatián (2004) e por Nogueira (2014), no que se refere à cooperação acadêmica, pode-se perceber a necessidade de se criar uma cultura da internacionalização. Isso, de modo que os parceiros da troca (Brasil e Timor-Leste) em situação de cooperação internacional, que ofertam dádivas e contradádivas, o façam conscientes daquilo de si que vai para o outro, daquilo do outro que vem para si e do compromisso assumido na relação horizontal da cooperação, a garantia da boa acolhida do que foi ofertado.

\section{Conclusões}

Diante do exposto, este artigo discutiu o processo de cooperação educacional entre Brasil e Timor-Leste a partir do paradigma do dom e da hospitalidade. Com base nessa observação, compreendeu-se que o Brasil construiu, ao longo das últimas décadas, um projeto de inserção internacional ancorada no plano da CSS. Nessa interface, a questão do Timor-Leste se configurou como um dos processos de cooperação relevantes em diversas dimensões - com destaque para o setor educacional.

Embora a agenda de cooperação educacional tenha iniciado nos governos anteriores, foi durante o governo Lula que se ampliaram e se aprofundaram as relações cooperativas do Brasil com o Timor-Leste no campo educacional. Na responsabilidade de tecer um olhar para o processo de cooperação entre ambos os países, este trabalho contemplou uma abordagem crítica, possibilitando lugar às dimensões endógenas, por vezes silenciadas em política externa, mas que se revelam como determinantes para o sucesso ou fracasso de um processo de cooperação. 
Refletir sobre a dimensão cotidiana e as interações sociais dos estudantes em situação de cooperação voltada para o desenvolvimento implica perguntar, tal como o faz Muñoz (2016), sobre o tipo de desenvolvimento que envolve a cooperação, quem o define, quem é beneficiado e a que tipo de interesses atende. Assim, é possível compreender melhor a CSS no campo educacional em múltiplas perspectivas: a dos Estados, das instituições e dos indivíduos.

Desse modo, tem-se que a CSS acadêmica entre Brasil e Timor-Leste representa, simultaneamente, uma importante ferramenta de soft power, um meio de produção de (boa) reputação internacional, a ampliação de possibilidades de estabelecer alianças/vínculos em diversas áreas, o aperfeiçoamento de quadros nas instituições envolvidas e na construção do Estado timorense, satisfação pessoal e experiência de vida agregada para os estudantes dos países de origem e de destino. Além disso, o contato com a alteridade leva à reflexão dos próprios parâmetros culturais dos envolvidos pessoalmente na situação de cooperação, assim como produz oportunidades de tolerância e aprendizagem com o "outro".

O olhar a partir do paradigma do dom e da hospitalidade revelou peculiaridades e desafios no processo de cooperação. A identificação de tais desafios pode auxiliar e aprimorar futuras políticas de cooperação internacional, seja no nível dos Estados ou das instituições. Ademais, espera-se que este trabalho estimule novas pesquisas plurimetodológicas - bibliográficas, documentais e etnográficas -, que poderão contemplar outros processos cooperativos a partir dos paradigmas do dom e da hospitalidade.

\section{Referências}

ASSOCIAÇÃO BRASILEIRA DE COOPERAÇÃO. Cooperação Brasil-Timor-Leste. Agência Brasileira de Cooperação. Brasília: MRE. 2012. Disponível em: [http://www.abc.gov. br/Projetos/CooperacaoSulSul/TimorLeste] Acesso em: 04 Jul. 2017.

ALDEN, Chris; MORPHET, Sally; VIEIRA, Marco A. The South in World Politics. Basingstoke: Palgrave Macmillan, 2010.

AMORIM, Celso. Brazilian foreign policy under presidente Lula (2003-2010): an overview. In: Revista Brasileira de Política Internacional, n. 53 - special edition, 2010, p. 214-240. Disponível em: [http://www.scielo.br/pdf/rbpi/v53nspe/v53nspea13.pdf]. Acesso em: 02 Jul. 2017. 
ANNAN, Kofi. Intervenções: uma vida de guerra e paz. Kofi Annan com Nader Mousavizadeh. Tradução de Donaldson M. Garschage, Renata Guerra. $1^{\text {a }}$ Ed. São Paulo: Companhia das Letras, 2013.

BARROS, Deolindo de; NOGUEIRA, Silvia Garcia. Cooperação educacional internacional Brasil/África: Do Programa Estudantes-Convênio de Graduação (PEC-G) à Universidade da Integração Internacional da Lusofonia Afro-Brasileira (UNILAB). In: Revista de Estudos Internacionais, vol. 6(2), 2015, p. 117-133.

BARTORÉO, Hanna J. A Língua Portuguesa em Timor: de que forma deve o ensino de português adaptar-se às diferentes realidades nacionais. In: Estudos Linguísticos, 4, Edições Colibri/CLUNI, Lisboa, 2009, p. 51-61.

BOURDIEU, Pierre. A distinção: crítica social do julgamento. São Paulo: EDUSP, 2007. BRACEY, Djuan. O Brasil e as operações de manutenção de paz da ONU: os casos do Haiti e Timor-Leste. In: Contexto Internacional. Vol. 33, $\mathrm{n}^{0}$ 2, 2011, p. 315-331.

BRASIL. MRE. Divisão de Temas Educacionais. Histórico do PEC-PG. 2015. Disponível em: [http://www.dce.mre.gov.br/PEC/G/historico.php]. Acesso em: 06 Jun. 2015.

BRICS POLICY CENTER, Centro de Estudos e Articulação da Cooperação Sul-Sul, Agência Brasileira de Cooperação. Caminhos para a construção de sistemas e processos de monitoramento e avaliação da cooperação sul-sul. Brasília, Ministério das Relações Exteriores, $1^{\text {a }}$ edição, Brasília, 2017.

BRUN, Élodie. Mudanças no panorama internacional por meio das relações Sul-Sul. Brasília: FUNAG, 2016.

BURGES, Sean. Brazil's international development co-operation: old and new motivations. In: Development Policy Review. v. 32, n. 3, 2014, p. 355-374.

BUTCHER, Jude et. al. Timor-Leste: Transforming education through partnership in a small post-conflict state. In: Comparative and international education: a diversity of voices. Volume 35. Rotterdam/Boston/Taipei: Sense Publishers, 2015.

CAILLÉ, Alain. Antropologia do dom: o terceiro paradigma. Petrópolis: Vozes, 2002.

CAIXETA, Marina Bolfarine. Cooperação Sul-Sul como nova tendência da cooperação internacional: o discurso e a prática da cooperação técnica do Brasil com São Tomé e Príncipe para o combate à tuberculose. Brasília: UNB, 2014. Disponível em: [http:// repositorio.unb.br/bitstream/10482/15924/1/2014_MarinaBolfarineCaixeta.pdf]. Acesso em: 01 Jul. 2017.

CAREY, Peter. Third-World Colonialism, the Geração Foun, and the birth of a new nation: Indonesia through east timorese eyes, 1975-99. In: Indonesia 76, 2003. p. 23-67.

CUNHA, João S. Carneiro. A questão de Timor-Leste: origens e evolução. FUNAG: Brasília, 2001. 
DCE/MRE. Departamento Assuntos Educadionais/Ministério das Relações Exteriores. Programas de Estudantes-Convênio de Graduação - PEC-G. Ministério das Relações Exteriores - MRE, 2019a. Disponível em: [http://www.dce.mre.gov.br/PEC/G/ historico/introducao.php]. Acesso em: 07 Jun. 2019.

DCE/MRE. Departamento de Assuntos Educadionais/Ministério das Relações Exteriores. Programas de Estudantes-Convênio de Pós-Graduação -PEC-PG. Ministério das Relações Exteriores - MRE, 2019b. Disponível em: [http://www.dce.mre.gov.br/PEC/PG/ historico.php]. Acesso em: 07 Jun. 2019.

DURAND, Fréderic. Histórias de Timor-Leste. Da pré-história à actualidade. Istória TimorLeste nian. Husi pre-istoria to’o atualidade. Lisboa: Lidel, 2009.

FHC. Discurso do senhor presidente da república, Fernando Henrique Cardoso, na sessão do conselho nacional do Timor-Leste. Díli, 22 de janeiro de 2001. In: Resenha de Política Exterior do Brasil, Departamento de Comunicações e Documentação: Coordenação de Documentação Diplomática, n. 88. Brasília: MRE, 2010. Disponível em: [http://www.mundorama.net/wp-content/uploads/2013/10/resenha-n881sem-2001.pdf]. Acesso em: 02 Jul. 2017.

GIACALONE, Rita. La Cooperacion Sur-Sur en La Agenda de Política Exterior de Brasil, Chile y Venezuela. In: Maria Regina Soares Lima, Carlos R.S. Milani, Enara Echart Muñoz (Eds.). Cooperación Sur-Sur, política exterior y modelos de desarrollo en América Latina. Ciudad Autónoma de Buenos Aires: CLACSO, 2016.

GODBOUT, Jacques. O espírito da dádiva. Lisboa: Instituto Piaget, 1992.

LAMAZIÈRE, Georges. A missão do Instituto Rio Branco. In: Curso para diplomatas africanos. Rio de Janeiro, 2012, p. 83-88.

LEITE, Iara C. Cooperação Sul-Sul: Conceito, História e Marcos Interpretativos. In: Observatório Político Latino Americano - OPLA. Observador On-line. Instituto de Estudos Sociais e Políticos - Rio de Janeiro: IESP/UERJ, 2012, p. 1-40. Disponível em: [http://obs.org.br/cooperacao/358-cooperacao-sul-sul-conceito-historiaemarc osinterpretativos]. Acesso em: 02 Jul. 2017.

LULA DA SILVA, Luiz I. Discurso do Presidente da República, Luiz Inácio Lula da Silva, durante visita ao Tribunal de Recursos do Timor-Leste. Díli, Timor-Leste, em 11/07/2008. In: Resenha de Política Exterior do Brasil. Ministério das Relações Exteriores, Departamento de Comunicações e Documentação: Coordenação-Geral de Documentação Diplomática. Brasília: Ministério das Relações Exteriores - MRE, 2010. Disponível em: [http://www.itamaraty.gov.br/images/ed_biblioteca/resenhas_peb/ Resenha_numero_103_2_2008.pdf]. Acesso em: 04 Jul. 2017.

MAUSS, Marcel. Ensaio sobre a dádiva. Forma e razão da troca nas sociedades arcaicas. In: Sociologia e Antropologia, v. II, São Paulo: Edusp, 1974. 
MENDONÇA, Filipe A. do Prado; MIYAMOTO, Shiguenoli. A Política Externa do Governo Geisel (1974-1979). In: Século XXI, 2 (2): 2011, p. 11-29.

MIGNOLO, Walter. Histórias Globais/projetos Locais. Colonialidade, saberes subalternos e pensamento liminar. Belo Horizonte: Editora UFMG, 2003.

MILANI, Carlos R. S.; CONCEICAO, Francisco Carlos da and M’BUNDE, Timóteo Saba. Cooperação Sul-Sul em educação e Relações Brasil-PALOP. Cad. CRH [online]. 2016, vol. 29, n.76, p. 13-32. Disponível em: [http://www.scielo.br/pdf/ccrh/ v29n76/0103-4979-ccrh-29-76-0013.pdf]. Acesso em: 11 Dez. 2018.

MONTANDON, Alain (dir.). Introdução. In: Alain Montandon (dir.), O Livro da Hospitalidade. Acolhida do Estrangeiro na História e nas Culturas. São Paulo: Editora Senac, 2011.

MUÑOZ, Enara Echart. Una visión crítica de la cooperación Sur-Sur, prácticas, actores y narrativas. In: Cooperación Sur-Sur, política exterior y modelos de desarrollo en América Latina. Maria Regina Soares Lima, Carlos R.S. Milani, Enara Echart Muñoz (Eds.). Ciudad Autónoma de Buenos Aires: CLACSO, 2016.

NOGUEIRA, Silvia Garcia. Cooperação educacional Brasil-Timor-Leste e a dádiva da hospitalidade paraibana: reflexões sobre uma experiência. In: Miriam de Oliveira Santos; Regina Petrus; Anita Loureiro de Oliveira. (Org.). Recortes interdisciplinares sobre migrações e deslocamentos. V. 1, 1ed. Rio de Janeiro: Leo Christiano Editora Ltda., 2014, p. 107-120.

OLIVEIRA, Henrique Altemani de. Política externa brasileira. São Paulo: Saraiva, 2005. PEPE, Leandro L.; MATHIAS, Suzeley K. O envolvimento do Brasil na questão timorense. In: Lusotopie, XIII(2). 2006, mis en ligne le 10 avril 2016, consulté le 02 juillet 2017. Disponível em: [https://lusotopie.revues.org/1389]. Acesso em: 02 Jul. 2017.

PEREIRA, Patrícia Barbosa; CASSIANI, Suzani; LINSINGEN, Irlan von. International educational cooperation, coloniality and emancipation: the Program Teacher Qualification and Portuguese Language Teaching in East Timor and the teacher education. In: Revista Brasileira de Pós-Graduação, Brasília, v. 12, n. 27, p. 193-218, abr. 2015. Disponível em: [http://ojs.rbpg.capes.gov.br/index.php/ rbpg/article/ view/499/pdf]. Acesso em: 01 Jul. 2017

PERROT, Dainelle. Dádiva. Hospitalidade e reciprocidade. In: Alain Montandon (dir.), O Livro da Hospitalidade. Acolhida do Estrangeiro na História e nas Culturas. São Paulo: Editora Senac, 2011, p. 63-72.

RAMANZINI JR, H. et. al. As diferentes dimensões da cooperação sul-sul na política externa brasileira. In: Política Externa Brasileira, Cooperação Sul-Sul e Negociações Internacionais. Haroldo Ramanzini Júnior; Luis Fernando Ayerbe. (Org.). 1ed. São Paulo: Cultura Acadêmica - UNESP, 2015, p. 15-52. 
RDTL. República Democrática de Timor Leste. Timor-Leste Population and Housing Census 2010. Series: Analytical Reports on Education, vol. 9. United Nations Population Fund - UNFPA, 2012. Disponível em: [http://www.statistics.gov.tl/wp-content/ uploads/2013/12/Education_Monograph.pdf]. Acesso em: 11 Dez. 2018.

REIS, Danilo Rodrigues. Cooperação educacional entre Brasil e Timor-Leste sob o paradigma do dom. Dissertação de Mestrado, Programa de Pós-Graduação em Relações Internacionais, Universidade Estadual da Paraíba, 2016.

RENZIO et. al. O Brasil e a Cooperação Sul-Sul: Como Responder aos Desafios Correntes. 2013. In: BRICS Policy Center - Policy Brief. Disponível em: [http://bricspolicycenter. org/homolog/uploads/trabalhos/5992/doc/1619030609.pdf]. Acesso em: 30 Jun. 2017. SANTOS, Roberta de Freitas; CERQUEIRA, Mateus Rodrigues. Cooperação Sul-Sul: experiências brasileiras na América do Sul e na África. In: História, Ciências, Saúde - Manguinhos, Rio de Janeiro, v.22, n.1, 2015, p. 23-47. Disponível em: [http:// www.scielo.br/pdf/hcsm/v22n1/pt_0104-5970-hcsm-22-01-00023.pdf]. Acesso em: 01 Jul. 2017.

SARAIVA, Mirian. G. As estratégias de cooperação Sul-Sul nos marcos da política externa brasileira de 1993 a 2007. In: Revista Brasileira de Política Internacional. Vol. 50 n. 2, 2007, p. 42-59.

SEBASTIÁN, Jesús. Cooperación e internacionalización de las universidades. Buenos Aires: Biblos, 2004.

SILVA, Antero Benedito da. Educação e desafios em Timor-Leste pós-colonial. In:. Timor - Professores sem fronteiras: pesquisas e práticas pedagógicas em Timor-Leste. Maria Denise Guedes [et. al.] (orgs.), Florianópolis: NUP/UFSC, 2015, p. 121-136.

SILVA, Kelly Cristiane. A cooperação internacional como dádiva. Algumas aproximações. Mana. In: Estudos de Antropologia Social, 14(1), 2008, p. 141-171.

SOARES, Christiano C. A influência do ordenamento jurídico brasileiro em Timor-Leste: contribuições para o direito fundamental à igualdade. 2016. In: II Congresso Internacional de Educação Inclusiva. Disponível em: [http://editorarealize.com.br/revistas/cintedi/ trabalhos/TRABALHO_EV060_MD1_SA12_ID2841_23102016195157.pdf]. Acesso em: 03 Jul. 2017.

UEPB. Universidade Estadual da Paraíba recebe novos estudantes do Timor Leste para estudar na instituição em 2015. 2015. Disponível em: [http://www.uepb.edu.br/ universidade-estadual-da-paraiba-recebe-novos-estudantes-do-timor-leste-paraestudar-na-instituicao-em-2015/]. Acesso em: 17 Jun. 2019.

UEPB. UEPB participa das comemorações dos 11 anos de restauração da idependência do Timor Leste. 2013. Disponível em: [http://www.uepb.edu.br/universidade-estadualparticipa-das-comemoracoes-dos-11-anos-de-restauracao-da-independencia-do-timorleste/]. Acesso em: 17 Jun. 2019. 
UNTL. Universidade Nacional Timor Lorosa'e. Cooperação - Acordos e Redes. Disponível em: [http://www.untl.edu.tl/pt/cooperacao/acordos-e-redes]. Acesso em: 28 Jul. 2017. VIGEVANI, Tullo; CEPALUNI, Gabriel. A política externa de Lula da Silva: a estratégia da autonomia pela diversificação. In: Contexto internacional, 29(2), 2007, p. 273-335. Disponível em: [http://www.scielo.br/pdf/cint/v29n2/v29n2a02.pdf]. Acesso em: 02 Jul. 2017.

ZANESCO, Karlla; SALOMÓN; Mônica. A cooperação universitária para o desenvolvimento. In: Carta Internacional, vol. 8, n. 1, 2013, p. 111-130. Disponível em: [https://cartainternacional.abri.org.br/Carta/article/view/84/62]. Acesso em: 11 Dez. 2018. 